\title{
THE FUNCTIONAL OUTCOME OF LOCKING VS NON-LOCKING DUAL PLATE FIXATION IN INTRA- ARTICULAR FRACTURE DISTAL END HUMERUS: A RETROSPECTIVE COMPARATIVE STUDY
}

\author{
Manish Bairagi ${ }^{1}$, Mahendra Panwar'2, Sameer Gupta ${ }^{3}$,Anand Rao 4 \\ ${ }^{1}$ Assistant Professor, Department of Orthopaedics, G. R. Medical College \& J. A. Hospital, Gwalior, Madhya Pradesh. \\ ${ }^{2}$ Senior Resident, Department of Orthopaedics, G. R. Medical College \& J. A. Hospital, Gwalior, Madhya Pradesh. \\ ${ }^{3}$ Professor \& HOD, Department of Orthopaedics, G. R. Medical College \& J. A. Hospital, Gwalior, Madhya Pradesh. \\ ${ }^{4}$ Post Graduate Student, Department of Orthopaedics, G. R. Medical College \& J. A. Hospital, Gwalior, Madhya Pradesh.
}

\section{ABSTRACT}

\section{BACKGROUND}

Despite all advances in treatment, it is a challenge to most of the orthopaedic surgeons to give better result in the management of distal end humerus intra-articular fractures, because it has complex anatomy. This study has been done to evaluate the functional outcome of double plate fixation with right angle to each other for intra-articular fracture of distal end humerus and compared with locking vs non-locking plate fixation.

\section{AIM}

This study has been done to evaluate the functional outcome of double plate fixation with right angle to each other for intraarticular fracture of distal end humerus with comparison of locking and non-locking plate fixation.

\section{METHODS}

This is retrospective comparative study done between 2006 and 2014 in the Department of Orthopaedics, G.R. Medical College and J.A. Group of Hospital, Gwalior (M.P.), India. All patients who were presented to Department of Orthopaedics with intra-articular fracture, distal end humerus fracture, medically fit patient who were of age group between 18-80 years of age with close or type 1 GA (Gustilo Anderson) compound fracture and fracture type AO type C were included. Other patients who sustained GA type 2 and 3 , severely comminuted and severe osteoporotic bone were excluded.

\section{RESULT}

A total no. of 60 patients. The age of patients ranged from 22 to 65 years. To classifying according to AO classification, 15 cases were of type C1, 39 were of type C2 and 06 were of type C3. The results were rated using Jupiter's criteria as excellent in 26 (43.3\%) cases, good in 16 (26.7\%), fair in 11 (18.3\%) cases and poor in $07(11.7 \%)$.

\section{CONCLUSION}

Double plate fixation is standard and effective method of treating intra-articular fracture of distal humerus, the method gives a stable fixation and allow early mobilization of elbow joint without risk of implant failure. In the study, there is no much advantage from the locking plate fixation in comparison with the non-locking plates.

\section{KEYWORDS}

Humerus, Distal, Intraarticular Fracture, Plate.

HOW TO CITE THIS ARTICLE: Bairagi M, Panwar M, Gupta S, et al. The functional outcome of locking vs non-locking dual plate fixation in intra-articular fracture distal end humerus: a retrospective comparative study. J. Evolution Med. Dent. Sci. 2016;5(53): 3511-3515, DOI: $10.14260 /$ jemds/2016/810

\section{INTRODUCTION}

Despite all advances in treatment, it is a challenge to most of the orthopaedic surgeons to give better result in the management of distal humerus intra-articular fractures, because it has complex anatomy. Wide range of treatment available from conservative to operative treatment Approximately, $7 \%$ of all adult fractures involve the elbow. Out of these, approximately $1 / 3^{\text {rd }}$ involve the distal humerus. In late 80 's, various authors came across with encouraging result of operative treatment for distal end humerus fractures reported by Jupiter et al (1985).(1) and Holdsworth BJ et al (1990).(2) Gabel et al (1987) have reported a method of

Financial or Other, Competing Interest: None.

Submission 01-01-2016, Peer Review 05-03-2016,

Acceptance 12-03-2016, Published 02-07-2016.

Corresponding Author

Dr. Manish Bairagi,

Assistant Professor

Department of Orthopaedics,

G. R. Medical College \& J. A. Hospital,

Gwalior, Madhya Pradesh.

E-mail: drmanish.ortho@gmail.com

DOI: $10.14260 /$ jemds $/ 2016 / 810$ fixation of these fractures using double plates with intercondylar screw. ${ }^{(3)}$

They claimed that the fixation was stable enough to start early mobilization leading to excellent-to-good result. Soon JK et al (2004) improved the AO technique for fixation of small intra-articular fragments, which made operation predictable and dual plate fixation in two plane has standard of treatment.(4) This study was done to evaluate the functional outcome of double plate fixation with right angle to each other for intra-articular fracture of distal end humerus were evaluated and those who fulfil the inclusion criteria were included in our study.

\section{METHODS AND MATERIALS}

This was a retrospective comparative study done between 2006 and 2014 in the Department of Orthopaedics, G.R Medical College and J. A. Group of Hospital, Gwalior (M.P.), India. All patients who were presented to the Department of Orthopaedics with intra-articular fracture distal end humerus fracture and medically fit, who were of age group between 1880 years of age with close or type 1 GA (Gustilo Anderson) 
compound fracture and fracture type $\mathrm{AO}$ and type $\mathrm{C}$ were included. Other patients who sustained GA type 2 and 3, severely comminuted and severe osteoporotic bone were excluded.

Careful history was taken from the patients, which related to other medical conditions, mode of injury and carefully examined the local area for wound and associated other injuries or fractures. Radiological evaluation was done in all cases by the Antero-Posterior, Lateral and Traction view of affected elbow, the fractures were classified according to OTA classification and the degree of comminution, displacement of fragments, condition of bone were noted. Elbow was initially immobilized in an above elbow posterior POP slab. All these patients were then subjected to surgery after pre-anaesthetic evaluation and preoperative antibiotics. The evaluation of functional outcome by Jupiter criteria (Table 1).

\section{Surgical Procedure}

The patient was given either brachial block/general anaesthesia. The patients were placed in the lateral decubitus position with the operative arm draped free, supported by pillow. A pneumatic tourniquet was used in all the cases. All cases were operated by trans-olecranon approach, a standard posterior incision was used extending from $12-15 \mathrm{~cm}$ above and $5 \mathrm{~cm}$ distal to the tip of olecranon full thickness skin flap were raised to reveal underlying fascia and olecranon. First ulnar nerve was carefully isolated before olecranon osteotomy and gently retracted.

The lower end of humerus was then exposed by either $\mathrm{V}$ shaped or transverse osteotomy of the olecranon. Articular fracture restoration by temporary fixation by K-wires done first and any loose small articular fragment was removed. Then intercondylar fixation was done by $4 \mathrm{~mm}$ lag screw. A non-lag screw was used in cases with intra-articular comminution. The fixation of condyles to metaphysis was done after careful reduction and two K-wire fixation on each side (Medial and lateral) at $45^{\circ}$ angle. The primary fixation of lateral (Postero-lateral) column was done by either molded $3.5 \mathrm{DCP} /$ reconstruction plate $/ 1 / 3^{\text {rd }}$ tubular plate or contoured 3.5 locking plate. But we usually preferred DCP/LCP, then additional fixation of medial column was done by either $1 / 3^{\text {rd }}$ tubular plate, reconstruction plate or medial locking plate.

The osteotomised olecranon was reduced and fixation was done by TBW. In some cases, ulnar nerve was transposed anteriorly. After closure of wound and dressing, POP posterior slab was applied and post-operatively limb was elevated.

First dressing was done on $3^{\text {rd }}$ postoperative day and started mobilization of elbow. Suture removal was done on 10 $12^{\text {th }}$ postoperative day, follow-up of patients was done every 15 days for first month and then every month for at least 6 months. At each follow-up, a thorough clinical and radiological evaluation was done. At six months postoperatively, clinical evaluation was done using Jupiter's criteria (Table No. 1).

\section{RESULT}

A total of 60 patients were included in our study who fulfilled the inclusion criteria. The age of the patient was ranged from 22 to 65 years with the mean age of 39.7 years. Males were the predominant in our study. There were 40 $(66.6 \%)$ males and $20(33.3 \%)$ with the mean age of the male patients was 37.2 years and female was 44 years. Right limb was involved more than left limb, right limb in $36(60 \%)$ and left limb involved in 24 (40\%) cases.

In our study major mode of trauma was self-fall, which was seen in $40(60.66 \%)$ cases. Other mode of injury were road traffic accidents in 19 (31.66\%) and assault in 01 (1.66\%) case.

According to AO (OTA) classification, 15 cases were of type C1, 39 were of type C2 and 06 were of type C3. In this study, we included the cases who had undergone trans-olecranon osteotomy approach to the fracture and no complication of olecranon osteotomy was seen. The results were evaluated using Jupiter's criteria as excellent in $26(43.3 \%)$ cases, good in $16(26.7 \%)$, fair in $11(18.3 \%)$ cases and poor in $07(11.7 \%)$.

In type $\mathrm{C} 1$ fractures patient had excellent outcome in 02 (13.3\%) cases, good in $04(26.7 \%)$, fair in $05(33.3 \%)$ and poor in $04(26.7 \%)$ cases. In type C2 fractures excellent outcome was seen in $21(53.8 \%)$ cases, good in 10 (25.6\%), fair in 05 (12.8\%), and poor in $03(7.7 \%)$ cases. Patients with type C3 fractures had excellent outcome in $03(50 \%)$ cases, good 02 $(33.3 \%)$ cases, fair $01(16.7 \%)$ cases and no poor outcome was seen.

In our study, out of 60 patients 26 were fixed with nonlocking plates and 34 patients were fixed with locking plates. In non-locking plate fixation group, excellent result was seen in $12(46.15 \%)$ cases, good in $09(34.6 \%)$ cases, fair in 02 $(7.7 \%)$ cases and poor in $03(11.53 \%)$ cases.

In locking plate fixation group $16(47.05 \%)$ had excellent result, good in 09 (26.47\%), fair in $05(14.70 \%)$ and poor in 04 $(11 \%)$ case. In both groups there was no significant difference in the functional outcome of these fractures, because result was depended on stable fixation and early mobilization of elbow joint.

The study demonstrates the effectiveness of double plate in securing a stable fixation in these difficult fractures, allowing early mobilization without risk of implant failure even in severely comminuted fractures of distal end humerus, thus giving better result than other treatment modalities for this fracture (Table No. 2-8).

\section{Complication}

Complications include 6 superficial infections, two in nonlocking group, while 4 in locking plate group, 3 deep infections seen in non-locking plate group, implant failure in only 1 patient in the locking plate group, ulnar nerve involvement was seen in 6 cases, 4 in non-locking plate group and 2 in locking plate group. Non-union of supracondylar region was seen in only 1 case of the locking plate group (Table No. 9).

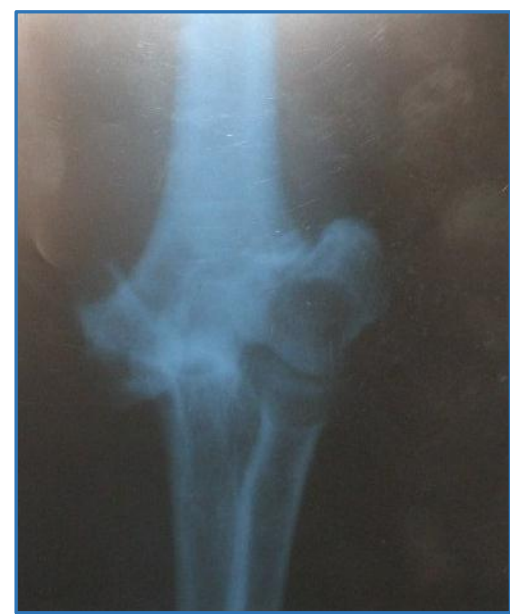

Pre-Operative X-Ray 


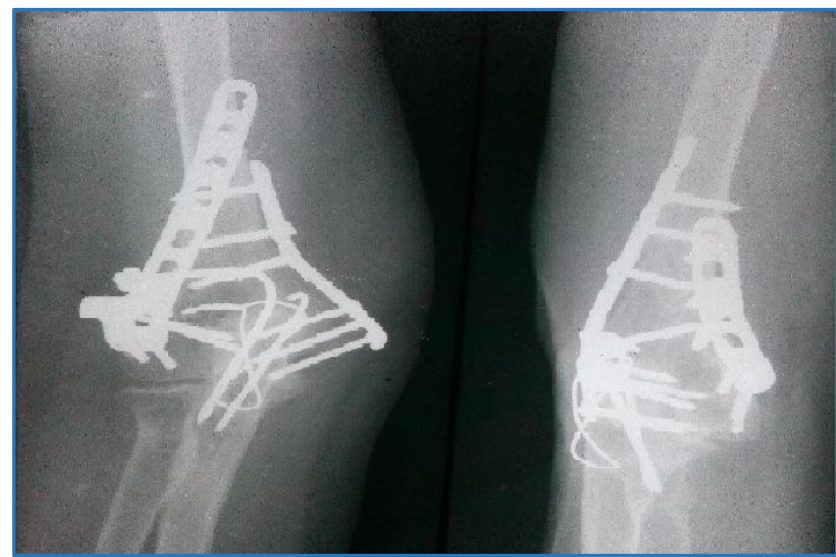

Post-Operative X-Ray

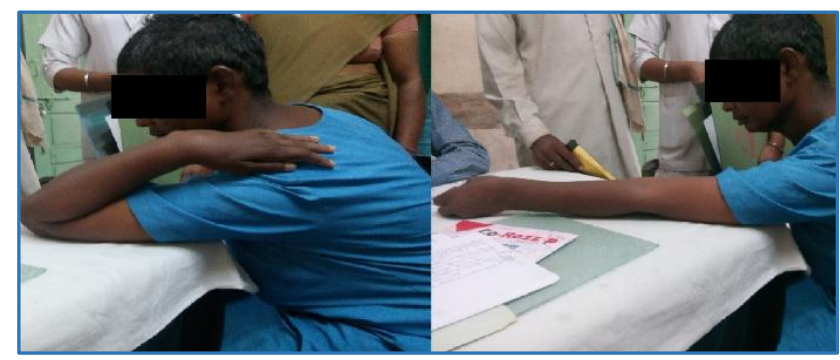

Functional Outcome

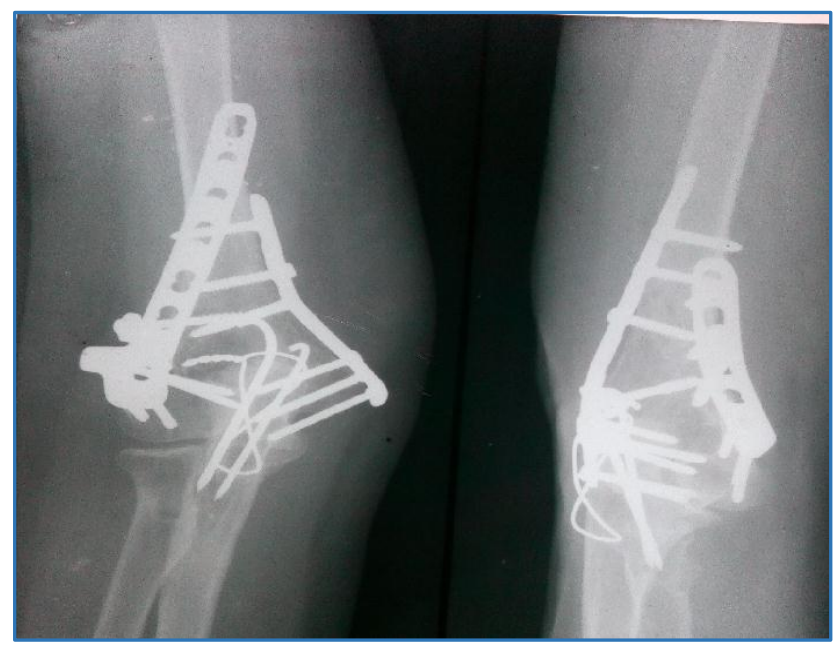

Post-Operative X-Ray
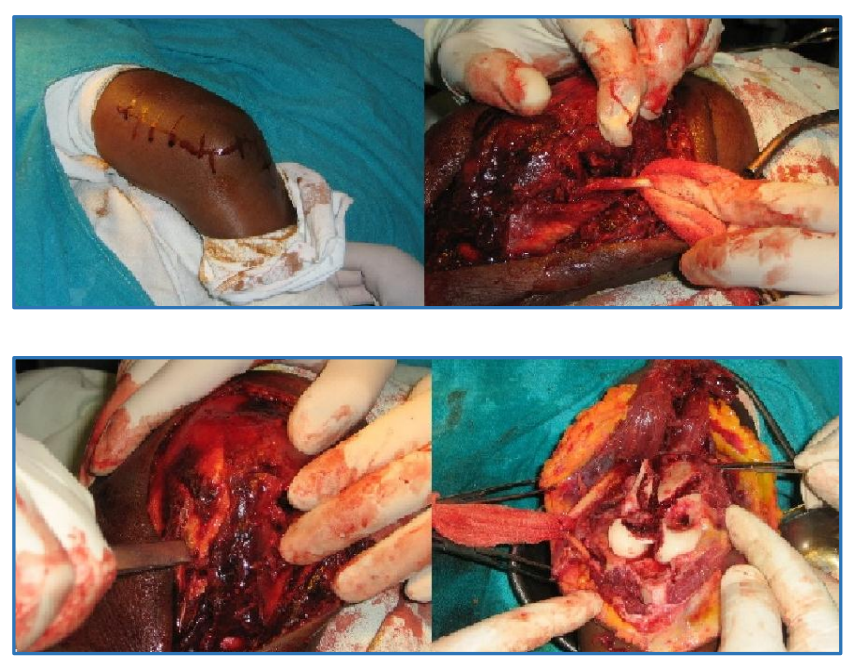

Intra-Operative Images

\begin{tabular}{|c|c|c|c|c|}
\hline Result & $\begin{array}{c}\text { Loss of } \\
\text { Extension }\end{array}$ & Flexion & Pain & Disability \\
\hline Excellent & $<15^{*}$ & $>130^{*}$ & None & None \\
\hline Good & $<30^{*}$ & $>120^{*}$ & slight & Minimal \\
\hline Fair & $<40^{*}$ & $>90^{*}$ & $\begin{array}{c}\text { With } \\
\text { activity }\end{array}$ & Moderate \\
\hline Poor & $<40^{*}$ & $>90^{*}$ & variable & Severe \\
\hline \multicolumn{5}{|c|}{$\begin{array}{c}\text { Table 1: Jupiter Criteria for } \\
\text { Evaluation of Functional Outcome }\end{array}$} \\
\hline \multicolumn{6}{|c|}{}
\end{tabular}

\begin{tabular}{|c|c|c|c|}
\hline $\begin{array}{c}\text { Age Group } \\
\text { (yrs.) }\end{array}$ & Male & Female & Total \\
\hline $18-30$ & $13(32.5 \%)$ & $06(30 \%)$ & $19(31.66 \%)$ \\
\hline $31-40$ & $14(35 \%)$ & $06(30 \%)$ & $20(33.33 \%)$ \\
\hline $41-50$ & $07(17.5 \%)$ & $05(25 \%)$ & $12(20 \%)$ \\
\hline $51-60$ & $06(15 \%)$ & $02(10 \%)$ & $08(13.33 \%)$ \\
\hline $61-70$ & $00(00 \%)$ & $01(5 \%)$ & $01(1.66 \%)$ \\
\hline $71-80$ & $00(00 \%)$ & $00(00 \%)$ & $00(00 \%)$ \\
\hline Total & $\mathbf{4 0 ( 6 6 . 6 6 \% )}$ & $\mathbf{2 0}(33.33 \%)$ & $\mathbf{6 0}(\mathbf{1 0 0} \%)$ \\
\hline \multicolumn{4}{|c|}{ Table 2: Distribution of Fracture } \\
According to Age and Sex \\
\hline
\end{tabular}

\begin{tabular}{|c|c|c|c|}
\hline Limb Side & Male & Female & Total \\
\hline Right & $25(65.5 \%)$ & $11(55 \%)$ & $36(60 \%)$ \\
\hline Left & $15(37.5 \%)$ & $09(45 \%)$ & $24(40 \%)$ \\
\hline \multicolumn{3}{|c|}{ Table 3: Distribution of Fractures } \\
According to Side Involved \\
\hline
\end{tabular}

$40(66.6 \%) 20(33.3 \%) 60(100 \%)$

\begin{tabular}{|c|c|c|c|}
\hline $\begin{array}{c}\text { Mode of } \\
\text { Trauma }\end{array}$ & $\begin{array}{c}\text { Male } \\
\text { No. of Patient } \\
(\%)\end{array}$ & $\begin{array}{c}\text { Female } \\
\text { No. of Patient } \\
(\%)\end{array}$ & Total \\
\hline FALL & $25(62.5 \%)$ & $15(75 \%)$ & $40(60.66 \%)$ \\
\hline RTA & $15(37.5 \%)$ & $04(20 \%)$ & $19(31.66 \%)$ \\
\hline Assault & $00(0 \%)$ & $01(05 \%)$ & $01(1.66 \%)$ \\
\hline Total & 40 (66.66\%) & $\mathbf{2 0 ( 3 3 . 3 3 \% )}$ & $\mathbf{6 0 ( 1 0 0 \% )}$ \\
\hline \multicolumn{4}{|c|}{$\begin{array}{c}\text { Table 4: Distribution of Fracture } \\
\text { According to Mode of Trauma }\end{array}$} \\
\hline
\end{tabular}

\begin{tabular}{|c|c|c|c|}
\hline $\begin{array}{c}\text { Type of } \\
\text { Fracture }\end{array}$ & $\begin{array}{c}\text { Male } \\
\text { No. of Patient } \\
(\%)\end{array}$ & $\begin{array}{c}\text { Female } \\
\text { No. of Patient } \\
(\%)\end{array}$ & Total \\
\hline C1 & $15(37.5 \%)$ & $00(0 \%)$ & $15(25 \%)$ \\
\hline C2 & $21(52.5 \%)$ & $18(90 \%)$ & $39(65 \%)$ \\
\hline C 3 & $04(12.5 \%)$ & $02(10 \%)$ & $06(10 \%)$ \\
\hline Total & $\mathbf{4 0}$ & $\mathbf{2 0}$ & $\mathbf{6 0}$ \\
\hline \multicolumn{4}{|r}{ Table 5: Type of Fracture According to A.O Classification } \\
\hline
\end{tabular}

\begin{tabular}{|c|c|c|c|c|}
\hline Result & C1 & C2 & C3 & Total \\
\hline Excellent & 02 & 21 & 03 & $26(43.33 \%)$ \\
\hline Good & 04 & 10 & 02 & $16(26.66 \%)$ \\
\hline Fair & 05 & 05 & 01 & $11(18.33 \%)$ \\
\hline Poor & 04 & 03 & 00 & $07(11.66 \%)$ \\
\hline Total & $\mathbf{1 5}$ & $\mathbf{3 9}$ & $\mathbf{0 6}$ & $\mathbf{6 0}$ \\
\hline \multicolumn{6}{|c|}{ Table 6: Functional Results (Jupiter's Criteria) } \\
\hline
\end{tabular}

\begin{tabular}{|c|c|c|c|c|}
\hline Result & C1 & C2 & C3 & Total \\
\hline Excellent & 04 & 06 & 02 & $12(46.15 \%)$ \\
\hline Good & 02 & 07 & 00 & $09(34.61 \%)$ \\
\hline Fair & 00 & 01 & 01 & $02(7.69 \%)$ \\
\hline Poor & 02 & 01 & 00 & $03(11.53 \%)$ \\
\hline Total & 08 & 15 & 03 & $\mathbf{2 6 ( 1 0 0 \% )}$ \\
\hline \multicolumn{7}{|c|}{ Table 7: Non-Locking Plates Result } \\
\hline
\end{tabular}




\begin{tabular}{|c|c|c|c|c|}
\hline Results & C1 & C2 & C3 & Total \\
\hline Excellent & 04 & 11 & 01 & $16(47.05 \%)$ \\
\hline Good & 01 & 06 & 02 & $09(26.47 \%)$ \\
\hline Fair & 00 & 05 & 00 & $05(14.70 \%)$ \\
\hline Poor & 02 & 02 & 00 & $04(11.76 \%)$ \\
\hline Total & 07 & $\mathbf{2 4}$ & $\mathbf{0 3}$ & $\mathbf{3 4 ( 1 0 0 \% )}$ \\
\hline \multicolumn{5}{|c|}{ Table 8: Locking Plates Result } \\
\hline
\end{tabular}

\begin{tabular}{|c|c|c|c|}
\hline No. & Complication & $\begin{array}{c}\text { Non- } \\
\text { Locking }\end{array}$ & Locking \\
\hline 01 & Sup. infection & 02 & 04 \\
\hline 02 & Deep infection & 03 & 00 \\
\hline 03 & Implant failure & 00 & 01 \\
\hline 04 & $\begin{array}{c}\text { Ulnar nerve } \\
\text { involvement } \\
\text { (Temporary) }\end{array}$ & 04 & 02 \\
\hline 05 & Myositis ossificans & 00 & 00 \\
\hline 06 & $\begin{array}{c}\text { Non-union of } \\
\text { supracondylar region }\end{array}$ & 00 & 01 \\
\hline 07 & $\begin{array}{c}\text { Non-union of } \\
\text { olecranon osteotomy }\end{array}$ & 00 & 00 \\
\hline \multicolumn{2}{|c|}{ Table 9: Complication } \\
\hline
\end{tabular}

\section{DISCUSSION}

We studied 60 patients with distal humerus intra-articular fractures and they were divided into two groups. One with the patients treated with locking plates and other with the nonlocking plates with 26 patients in non-locking plate group and 34 in locking group. Trans-olecranon approach was used in all the cases and dual plates right angle to each other. Fixation at right angle to each other to provide strong biomechanical construct in two coronal and sagittal plane. All patients were followed up for a minimum period of 6 months and result was evaluated using Jupiter's score based on range of motion (Flexion, Loss of Extension), Pain and Disability.(1)

Early surgical intervention, anatomic restoration of the articular surface and rigid internal fixation with early aggressive physical therapy appears to be the recipe for the best surgical outcomes in intra-articular distal humeral fractures.(5) This was advocated by Cassebaum in 1952. Aitken and Rorabeck further demonstrated that prolonged immobilisation resulted in poor outcome.

In 2004, J. L. Soon et al reviewed 15 patients with intraarticular distal humerus fractures treated surgically, of which three required subsequent re-fixation and four underwent joint mobilisation surgery. The mean arc of flexion of patients with type $\mathrm{C}$ fractures following primary fixation was $92.5^{\circ}$ ranged from $45-140^{\circ}$, whilst the type $B$ group have a mean arc of $110^{0}$ ranged from $60-145^{\circ}$. The sub-group of type $C$ patients without revision surgery had a mean flexion arc of $110.7^{0}$ ranged from $95-140^{\circ}$ with $100 \%$ Good-to-Excellent scores. Overall, $86.7 \%$ Good-to-Excellent results was achieved in their study.(4)

In our study we achieved excellent-to-good result in $57 \%$ cases, fair in $19 \%$ and poor in $12 \%$ cases, while functional outcome does not have significant differences whether fixed by non-locking and non-locking plate in reference to ROM, pain and stability; however, locking plate fixation have significant role in stability in fixation of especially compromised bone quality, but in our study most of the patients more than $50 \%$ in age group between $20-40$ years.
In 1990, Helfet et al compared three commonly used configurations of various implants used for fixation of distal humeral fractures. The double plate construct, irrespective of plate type was significantly stronger, both in rigidity and fatigue testing than cross screws or the single " $\mathrm{Y}$ " plate. If rigid stabilization of supracondylar or bicondylar distal humeral fractures is desired, then two plate constructs at right angles are biomechanically optimal.(6) Hence, in our study two most important points for the better outcome were anatomic restoration of intercondylar fracture, distal end humerus by interfragmentary transverse $4 \mathrm{~mm}$ cc screw fixation with compression to allow to convert the fracture from type $\mathrm{C}$ to type $\mathrm{A}$ and plates were made to fit the contour of the distal humerus.

In 1993, Helfet et al in his study obtained a reproducible results. The average excellent-to-good results with surgical treatment for Type $\mathrm{C}$ fractures was $75 \%$ ranged from $65-$ $100 \%$. Complications include heterotopic ossification in $4 \%$ cases, infection in $4 \%$, ulnar nerve palsy in $7 \%$, failure of fixation in $5 \%$ and non-union in $2 \%$ cases. ${ }^{7}$ )

In our study we had complications in 17 cases, 9 in nonlocking plate group and 8 in locking plate group. Complications include 6 superficial infection, two in non-locking group, while 4 in locking plate group, 3 deep infections seen in non-locking plate group, implant failure in only 1 patient in the locking plate group, ulnar nerve involvement was seen in 6 cases, 4 in non-locking plate group and 2 in locking plate group. Nonunion of supracondylar region was seen in only 1 case of the locking plate group.

Though, the series is small comprising of only 60 cases and the study demonstrate the effectiveness of double plate in securing a stable fixation in these difficult fractures, allowing early mobilization without risk of implant failure even in severely comminuted fractures of distal end humerus, thus giving better result than other treatment modality for this fracture.

\section{CONCLUSION}

Double plate fixation is the standard and effective method of treating intra-articular fracture of distal humerus. The procedure is relatively difficult and requires skill to restore anatomical congruence of articular surface. The method gives a stable fixation and allows early mobilization of elbow joint without risk of implant failure. The posterior trans-olecranon approach is safe and provides wide exposure of intra-articular surface of distal humerus. The risk of non-union olecranon osteotomy can be minimized by using tension band wiring to fix the olecranon. Ulnar nerve must be carefully isolated as there is risk of injury to it. We have seen that there is no much advantage from the locking plate fixation in comparison with the non-locking plates with respect to the functional outcome apart from the stable fixation. Complications in our study is minimal and can be controlled by meticulous intra-operative and post-operative care.

\section{REFERENCES}

1. Jupiter JB, Nelf U, Holzach P, et al. Intercondylar fracture of humerus an operative approach. J Bone Joint Surg 1985;67(2):226-39.

2. Holdsworth BJ, Mossad MM. Fracture of adult distal humerus elbow function after internal fixation. J Bone Joint Br 1990;72(3):362-5. 
3. Gabel GT, Hanson G, Bennett JB, et al. Intraarticular fracture of distal humerus in adult. Clin orthop relat res 1987;216:99-108.

4. Soon JL, Chan BK, Low CO. Surgical fixation of intraarticular fracture of distal humerus in adult. Injury 2004;35(1):44-54.

5. Cassebaum WH. Operative treatment of T \& Y fractures of the lower end of humerus. Am J Surg 1952;83:265-70.
6. Helfet DL, Hotchkiss RN. Internal fixation of the distal humerus: a biomechanical comparison of method. Journal of Orthopaedic Trauma 1990;4(3):260-4.

7. Helfelt D, Schmelinh G. Bicondylar intraarticular fractures of the distal humerus in adults. Clinical Orthopaedics and Related Research \&NA 1993;292:26-36. 